\title{
Finger dialogue. The embodied accomplishment of learnables in instructing grammar on a worksheet
}

\author{
Ali Reza Majlesi
}

\section{Linköping University Post Print}

\section{Tweet}

N.B.: When citing this work, cite the original article.

Original Publication:

Ali Reza Majlesi, Finger dialogue. The embodied accomplishment of learnables in instructing grammar on a worksheet, 2014, Journal of Pragmatics, (64), 35-51.

http://dx.doi.org/10.1016/j.pragma.2014.01.003

Copyright: Elsevier http://www.elsevier.com/

Postprint available at: Linköping University Electronic Press http://urn.kb.se/resolve?urn=urn:nbn:se:liu:diva-104917 


\title{
Finger dialogue. The embodied accomplishment of learnables in instructing grammar on a worksheet
}

\begin{abstract}
This study is about embodied and endogenous grammar instruction on worksheets in teaching Swedish as a second language. It is demonstrated how an 'awareness' to produce a linguistic construct 'grammatically correct' is co-achieved by the teacher and the student. To see and understand the grammatical features of the words, an interactive instructional sequence is initiated by the teacher. This interactive scaffolding between the teacher and the student, to use meta-talk and to talk about abstract grammar, requires some concrete referents on a surface jointly attended to, and which are seen, pointed to and talked about. It is shown in detail how the interactional business of the interchange is dependent upon a constant integration of talk, gesture and orientation to the written grammatical construct on a sheet of paper. Teaching grammar is, thus, done through the objectification of quite abstract linguistic units and categories, and the transposition of the abstraction onto tangible and visible objects on the paper. Therefore, the result of the organization of order in instruction is a moment-by-moment sense-making, including accounting
\end{abstract}


for how to understand a grammatical phrase, and the rationale behind the relations of the grammatical constructs, and, also, transforming the organization of knowledge. This study shows that foregrounding grammatical learnables on a paper are actualized by the mobilization of diverse semiotic resources resulting in seeing, understanding and reaching an instructed vision ( $c f$. Goodwin, 1994) as the progressive achievement of observable and reportable embodied actions (Garfinkel, 1967, 2002). Grammatical learnables are, therefore, the procedural outcome of the hands-on practices as mutually achieved embodied accomplishments.

\section{Keywords:}

Instructed vision, Instructing grammar, Interactive scaffolding, Pointing gestures, Conversation analysis, Ethnomethodology, Multimodal interaction analysis

\section{Introduction}

The general aim of this study is to show, in detail, how 'awareness' about grammatical glosses, relations and rules are progressively accomplished in face-to-face teaching moments. The analysis will demonstrate how instructing second language grammar and accomplishing grammatical understanding on a worksheet are underwritten by embodied practices.

Research on social interaction in pedagogical activities has begun to analyze the organization of activities around documents and other artifacts, and also the organization of bodily actions in connection with, and with an orientation to those documents (see e.g. Churchill, Okada, Nishino, \& Atkinson, 2010; Svinhufvud \& Vehviläinen, 2013). The present study will focus on how a 'pedagogical setup' is co-built through embodied 
instructions and instructed actions to accomplish what is there on the grammar worksheet' for the learner to learn. What is highlighted is not only the mobilization of verbal and nonverbal resources for the elucidation and elaboration of the written grammatical constructs and their grammatical categories and relations, but also how these embodied practices are used in the instructions and what they do to the instructions ( $c f$. Garfinkel, 2002: 207). To do so, I analyze the design of actions in two instructing occasions in Swedish as a second language classroom.

Based on a detailed analysis of some video-recordings, this study will show how a teacher through her embodied practices opens an interactional space and invites the student to orient to, and recognize some grammatical categories, relations and rules as the pedagogical foci, i.e. 'learnables' (Majlesi \& Broth, 2012; Szczepek Reed, Reed \& Haddon, 2013; Zemel, \& Koschmann, 2014). The participants' bodily actions are reflexively mobilized to foreground, and make connections, not only between the visible written objects on the paper, but also between them and their grammatical glosses.

Doing being a teacher and a student are experiences which are lived in and through the instructing activity as an inter-corporeal co-operation. The teacher's and the student's procedural methods for 'seeing' and 'recognizing' learnables include some coordinated recognizable actions made of diverse semiotic resources such as talking, pointing at the written words and multi-modally operating on them together.

In co-present instructional 'joint projects' (H. Clark, 1996: 191), the teacher and the student temporize their actions according to the contingency of the instructing activity. Their actions are reflexive to the exhibition of joint attention to the common locus of the interactional focus. They remedy misunderstandings and solve problems as they proceed with the instructing activity. They objectify and make tangible the abstract 
categories. The linguistic forms are, therefore, accomplished to be 'seen as' (cf. Wittgenstein, 1953/2009: 204-208, and 217) certain glosses and categories as expressing some grammatical relations. These practices are the documentary evidence that demonstrably show how the student is provided with an instructed vision (cf. Goodwin, 1994) to see the words, their categories, and their relations as particular kinds of learnables.

Attending to the mobilization of diverse semiotic resources, and in order to examine their effects in the progressivity of instructed actions, the present study takes a qualitative, dialogical (interactional-contextual, see Linell, 2009), and praxeological perspective (Garfinkel, 1967; Sacks, 1992a, b). That is, the study adopts Ethnomethodology (a.k.a EM, see Garfinkel, 1967, 2002), Conversation Analysis (a.k.a. CA, see Sacks, Schegloff, \& Jefferson, 1974; Sacks, 1992a, b), and an action-based multimodal analysis (see e.g. Goodwin, 1981, 2000, 2007, 2013; Mondada, 2007, 2010; Broth \& Mondada, 2013) to show the details of how instructing grammar is done. That is how in-situ and in-vivo (Garfinkel, 2002: 203) such a praxeological environment is created.

\section{Background}

In language learning research, interaction is now considered 'a "priming device", allowing learners to focus attention on areas they are "working on"' (Gass \& Selinker, 1994/2008: 354). It has, therefore, become increasingly central in the examination of learning (see Firth \& Wagner, 1997; Markee, 2000; Seedhouse, 2004; Hall, Hellermann \& Pekarek Doehler, 2011, Koschmann, 2011; inter alia). Moreover, it has been argued that understanding the social mechanism of learning requires careful studies of how it is actualized in its various social contexts (see Donato, 2000), meaning that learning as a social activity should be studied in its 
own network of social relations and actions, with participants' real practices, i.e. in its social setting (see e.g. Firth \& Wagner, 1997; Mondada \& Pekarek Doehler, 2004; Sahlström, 2011; Melander, 2012; inter alia). More specifically, working out members' methods and their embodied practices in doing grammar instruction in co-present face-to-face interaction entails attending to various semiotic resources including talk, bodily actions, and the use of artifacts. In the studied setting, talk, pointing gestures and the use of pen and paper are demonstrably relevant for instructing grammar. Each of these resources in the organization of activities has its own history of research.

The importance of the use of documents e.g. in organizing activities (e.g. Garfinkel \& Bittner, 1967; see also Mondada 2012), in the management of business (Weber, 1968/1978), or constructing scientific knowledge (Latour \& Woolgar, 1979) has been investigated before. Within the pedagogical field, although scantly, the role of documents in the organization of instruction is gradually receiving analytic attention, while the study of embodied actions in pedagogical settings are abundant (see e.g. Alibali, Kita, \& Young, 2000; Singer \& Goldin-Meadow, 2005; Lazaraton, 2004; Gullberg, 2008; Seo, 2011; inter alia).

In academic supervision meetings, for instance, it is demonstrated how a constant orientation to inscriptions, particularly in the openings of these encounters, may promote pedagogical implications and elicitations (Svinhufvud and Vehviläinen, 2013). In a dyadic grammar tutoring over a worksheet, it has also been shown how orientating to the grammar worksheet as a cognitive resource is part of the process of learning in sociomaterial worlds (Churchill et al., 2010).

The use of documents, and the orientation to them in various activities are also shown to be accompanied by the use of gestures (e.g. Mondada, 2012). Gestures themselves have been the objects of a longstanding 
research history, from comparative cultural experimental studies (e.g. Efron, 1941/1972), to cognitive semiotic approaches (e.g. McNeill, 1992), and more interactional perspectives (e.g. Kendon, 1990).

In second language learning research, whereas the attention to the impact of documents in learning, from an interactional perspective, has been scarcely examined, the number of studies that examine the integrative impact of gesture and speech on learning has increased in recent years (for an overview, see Gullberg \& McCafferty, 2008; Gullberg, 2008). From a cognitive perspective, there are some studies that consider the role of gesture as either auxiliary to talk, or instrumental in language learning (see Gullberg \& McCafferty, 2008: 135; Gullberg, 2008: 280; see also Alibali, Kita, \& Young, 2000; $c f$. Singer \& Goldin-Meadow, 2005 for the use of gesture as to the improvement of learning in general). From a social perspective, there are also other studies (e.g. Lazaraton, 2004; Seo, 2011) which show that, and how, gestures and talk inform each other in doing learning activities, rather than being understood as phenomena of discrete communicative orders.

From an interactional perspective, several studies have highlighted aspects of instruction-in-action focusing on embodied practices. For instance, it has been shown that, in instructional settings, 'understanding' is an embodied situated phenomenon that is orderly displayed in sequences of actions (e.g. Mondada, 2010). What is understood and learned may be exhibited and observed in the student's production as an embodied achievement (e.g. Lindwall \& Ekström, 2012; cf. Keevallik, 2010).

As regards second language learning research on grammar, even though cooperative learning (Gagné \& Parks, 2013) and the role of scaffolding (Bruner, 1975; see also Donato, 2000) have been considered crucial to teaching and learning grammar, other resources than talk have not been systematically studied. Research has given importance to 
linguistic forms (e.g. White, 2003), learners' conscious awareness of those forms and structural rules (e.g. Krashen, 1981), learners' noticing the forms of the second language (e.g. Schmidt, 2001; Mori \& Hayashi, 2006), or their attention to different parts of its grammar (e.g. Swain, 1985; Gass, Svetics, \& Lemelin, 2003). However, the multimodal analysis of the role of papers and bodily actions, and their interplay for teaching and learning second language grammar are still scant (see, however, Churchil et al., 2010; Svinhufvud and Vehviläinen, 2013).

In line with previous EM/CA work on different learning activities, this study is going to show how this 'attention to', 'awareness of', or 'noticing of' grammatical forms and their relations are 'placed in the context of lived experience of participation' (Melander, 2012: 232; cf. Goodwin, 2000, 2007, 2013; Mondada \& Pekarek Doehler, 2004; Sahlström, 2011). It will be shown how in a co-present activity, the social phenomenon of instructing grammar is achieved in and through embodied actions.

\section{The video data and its transcription}

The data used for the study was extracted from a series of video recordings of activities in Swedish for Immigrants (SFI) classes. SFI is a course designed and sponsored by the Swedish state for adult foreigners to learn Swedish.

Data collection procedures followed the ethical recommendations of the Swedish Research Council (2011). The data are from the elementary (D) levels, corresponding with B1 levels in the Common European Framework of Reference for Languages (CEFR).

The chosen excerpts were digitized and transcribed using transcription notations for verbal and nonverbal behavior (see Appendix, $c f$. e.g. Sacks, et al., 1974; Goodwin, 1981; Mondada 2007). 'Multimodal' aspects are set 
in parentheses or a separate line to represent gaze, gesture and other nonverbal conduct that are relevant for the analyses. For analytic purposes, pictures and drawings are used to demonstrate the participants' relative positions and aspects of their embodied behavior.

\section{Analysis}

In what follows, it will be demonstrated how particular grammatical issues can be mutually and sequentially accomplished, as they are progressively evolving into learnables. The procedural activity in each sequence is comprised of reciprocated actions which are made co-operatively by the teacher and the student together on a sheet of paper.

\subsection{The worksheet as a resource for instructing grammar}

The first case to be considered is a conversation between a teacher and a student about the upshot of a grammar task. The task is an exercise on a worksheet with a list of incomplete sentences where the students fill in the blanks with words given in lexical base forms (fig. 1) to produce grammatically correct adverbs and adjectives. In Swedish, adverbs and adjectives get inflected in agreement with the subject or the following noun phrase.

Prior to the excerpt, repeating what has already been taught to the students, the teacher writes a few examples and some formulations on the whiteboard such as 'adjectives modify nouns', 'adverbs modify verbs and also adjectives'. She, then, goes around checking how the students are

doing and soon gets into a conversation with one of the students. The conversation is about how the student is to understand 'fantastiskt' (wonderfully) as an adverb modifying the adjective but not the verb in the 
sentence 'Kalle målar fantastiskt fina tavlor' (Kalle paints wonderfully nice paintings).

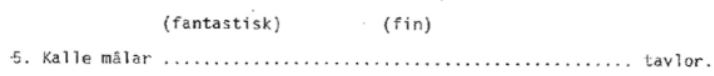

Fig. 1 The given sentence whose blank parts should be filled up with appropriate forms of the words in the parentheses.

To instruct the student, the teacher starts at the end of the phrase "fantastiskt fina tavlor" (wonderfully nice paintings), and step-by-step explains the structure of the noun phrase on the grammar worksheet by parsing the phrase backward from its grammatical head.

\section{Excerpt 1. Learning Adverb: Tape Gn, D-level}

Participants: Teacher (Tea) and Student (Stu)

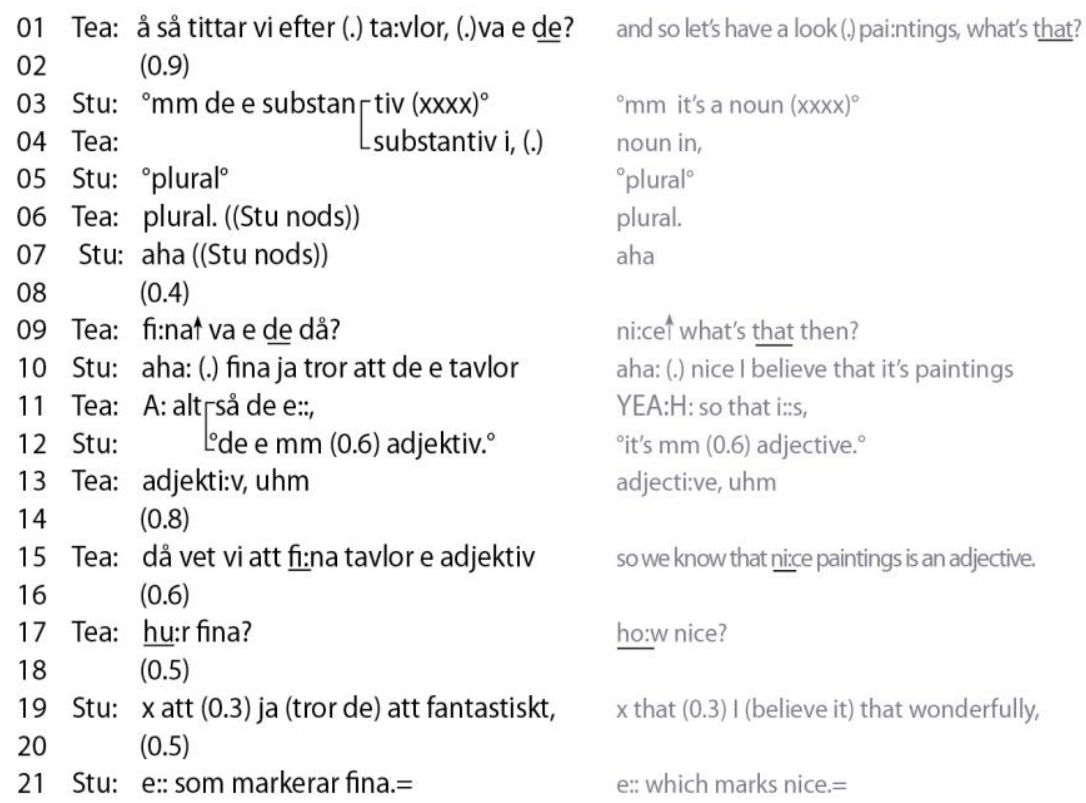


22 Tea: $=\mathrm{j}$

23 Stu:

24 Tea:

26 Tea:

27 Stu:

28

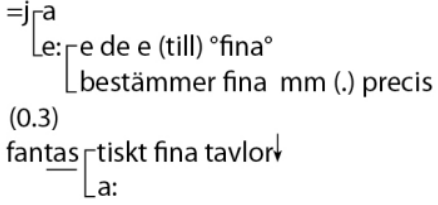

(0.7)
$=$ yes

e e it's (to) ${ }^{\circ}$ nice ${ }^{\circ}$

determines nice $\mathrm{mm}$ (.) exactly

wonderfully nice paintings $\downarrow$

The short conversation above between the teacher and the student is an instructing activity that is made of three parts, i.e. three constituent sequences (lines $1-7 ; 8-14 ; 14-28$ ) that progressively build the instruction's gestalt. These sequences are organized around a task, and shaped by the reciprocal interactional efforts of the parties. They are aimed at solving a grammatical problem, and reaching an understanding about the rationale behind the use of the adverb and the adjective in the target sentence.

A crucial claim here is that, to uncover the methods used by the teacher and the student for accomplishing this grammar instructional activity, examining the talk is not enough. Rather, we need to study the embodied participation framework (Goodwin, 2000), composed of the participants' talk, gazes, gestures (esp. pointing gestures) and their bodily orientations to the grammar worksheet. The worksheet is itself, of course, a kind of a semiotic structure designed for the practical purpose of invoking particular types of actions. 

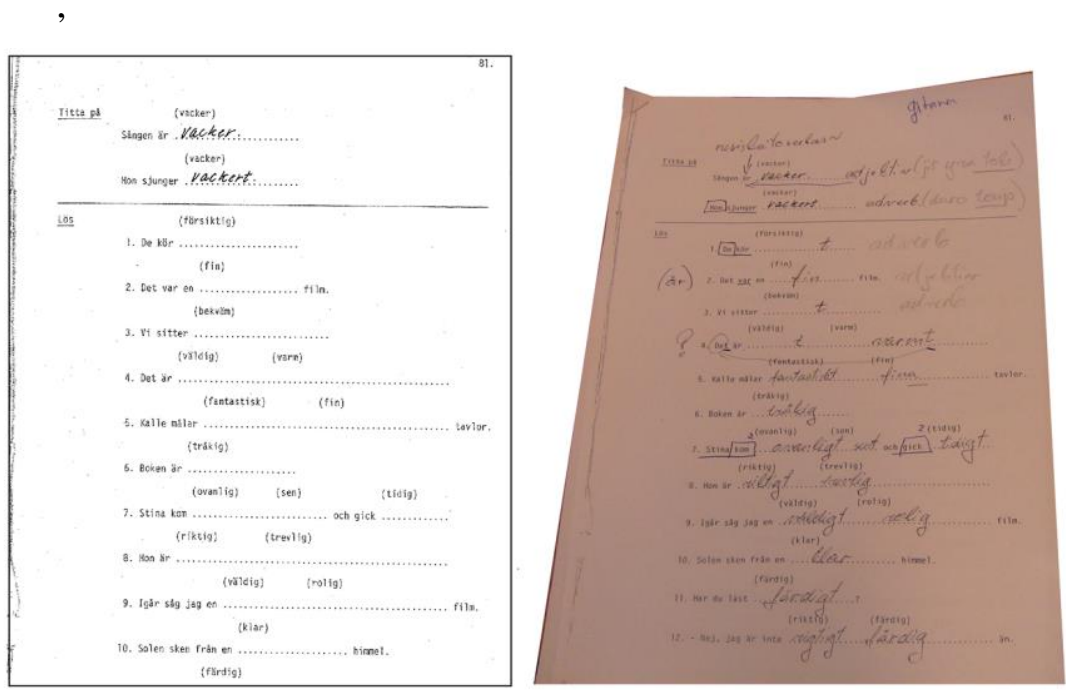

Fig. 2 The grammar worksheet before and after it is filled by notes, lines, circles, arrows, etc.

The paper may look simple enough, but it provides for a rich and complex interaction which reenacts and reinforces a historically sedimented account of language (a pro forma rule-and-principle-biased account). It does this by delivering some exemplar-based sentential know-how of Swedish grammar. It is also rich and complex in terms of being a sort of communicative and cognitive technology environment (cf. A. Clark, 2001; Churchill et al., 2010) within which certain instructing/learning activities are supposed to be carried out. It is rich and complex because the surface of the grammar worksheet is lumping together inference-rich (Sacks, 1992a: 40), context-specific signs, terms and linguistic concepts and categories for those who know how to read them.

The design of the worksheet, moreover, presupposes the students' adequacy of knowledge in understanding how to deal with the worksheet and knowing some parts of it, and it focuses on a particular part of grammar and predicts students' possible difficulties in that area. The worksheet as a semiotic field and as a locus of attention for producing 
relevant actions ( $c f$. Goodwin, 2000, 2013) is crucial in understanding the design of the embodied and endogenous actions in the instructing activity.

In the following sections, I will detail how the teacher and the student interactively use mutually elaborating embodied and material resources to produce together a shared grammatical understanding.

\subsection{Producing a grammatically correct phrase as an embodied accomplishment}

As explained above, the teacher and the student focus on how the adverb 'fantastiskt' (wonderfully/fantastically) in the sentence 'Kalle målar fantasktiskt fina tavlor' (Kalle paints wonderfully nice paintings) should be heard as belonging to the noun phrase 'fina tavlor'. This is achieved through their progressive inter-action. The teacher first draws the student's attention to the noun in the phrase, i.e. to the head of the phrase. She begins her instruction, with an initial move, as she says å så tittar vi efter (.) (and so let's have a look (.)).

Excerpt 1a. Learning Adverb: Tape Gn, D-level (line1)

Participants: Teacher (Tea) and Student (Stu)

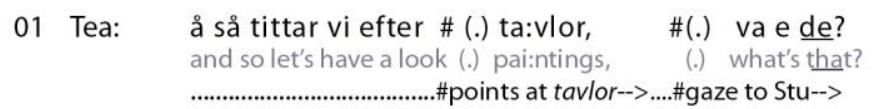

In some detail, the teacher's utterance starts with $\stackrel{a}{a}$ (and) which is a connective discourse marker - an indicator of the contiguity of the forthcoming action(s) in relation to the previous activity (Heritage and Sorjonen, 1994). It immediately gets followed by 'så' (so) which arguably foreshadows that what emerges next, even though as a new product/sequence/action is concomitant with, and ensues from, the previous 
action(s). As part of a continuous activity, it relates the upcoming action to the talk the parties had prior to the current activity, which was also about how to inflect adjectives and adverbs in Swedish. With that initiation, comes an invitation for mutual orientation to 'tavlor' (paintings): 'let's have a look (.) paintings', (.) (tittar vi efter (.) ta:vlor,(.) - line 1).

The production of the word 'tavlor' is made also by some specific prosodic features. It is articulated with an interactional (micro-)pause before and after, and also marked with a lengthened [a] and a small rise in the pitch at the end. These moves are symbiotic with the act of pointing to the word 'tavlor'. The pointing and the emergent talk jointly achieve the topic for the question that is still to come. In a way, when the written word 'tavlor' is pointed at and read out loud, it could be seen as a 'prospective indexical' (Goodwin, 1996). This prospective orientation is then also effectively formulated in the question ' $v a$ e de? ' (what's that?).

At this moment, the participation framework encompasses not only the attention of the interactants to each other, to the worksheet, and to the emerging project, but also the particular attention to a written word and its quality/features which transpire as the first item to address in the whole instruction.

A close observation shows how offering 'tavlor' as an instructional focus is done through the teacher's embodied action: the teacher's left index finger starts pointing at 'tavlor' exactly when she starts her turn. Her finger lands just below the word on the paper and she points at it with a pen from above before she articulates it. The finger on the sheet is stably kept below the word until toward the end of the sequence. In this way, the word 'tavlor' is treated as a significant resource for progressing the instruction, as a building block of 'what-is-here-to-learn' which is going to be progressively uncovered. The emergent talk and the pointing, therefore, by virtue of exhibiting an instructional focus, also indicates 'tavlor' as a 
prospective learnable. The teacher's operation on 'tavlor' and the student's co-operation are the starting point for a new configuration of how relevantly to understand the words on the worksheet:

Excerpt 1b. Learning Adverb: Tape Gn, D-level

Participants: Teacher (Tea) and Student (Stu)

01 Tea:

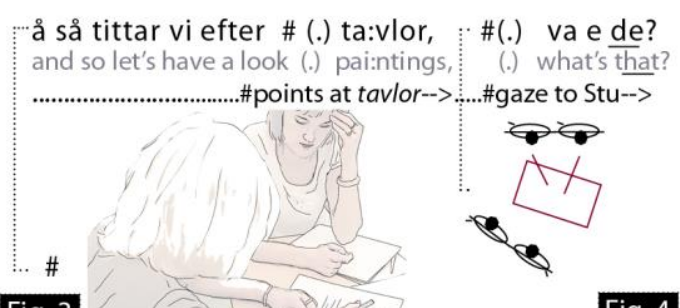

Fig. 3

Fig. 4

$02 \quad(0.9)$

03 Stu: $\quad{ }^{\circ} \mathrm{mm}$ de e substan $-\mathrm{tiv}(\mathrm{xxxx})^{\circ}$

04 Tea: $\quad \mathrm{mm}$ it's a no $\begin{gathered}\text { un }(\mathrm{xxxx})^{\circ} \\ \text { substantiv } \mathrm{i},(.) \\ \text { noun in, (.) }\end{gathered}$

05 Stu: $\quad{ }^{\circ}$ plural ${ }^{\circ}$

06 Tea: plural. ((Stu nods))

07 Stu: aha ((Stu nods))

As shown in the transcript (fig. 3), the double pointing gestures act conspicuously in the service of singling out a word in the syntactic structure as a mutually oriented object and partly in the service of what might be called a 'manifesting action' (H. Clark, 1996: 167), foregrounding 'tavlor' and highlighting its grammatical significance. These pointing gestures function a) to identify an object as a referent, b) to serve as a localizer and place-holder, a sustaining device for ongoing relevant talk to secure mutual orientation, and c) to project that something relevant to the identified object is forthcoming.

The instructional significance of 'tavlor' is recognized under the provisions of its indexicality (Garfinkel, 2002: 204), and accountably 
described or reflexively established as a 'plural noun'. It is a crucial component for the practical purpose of the grammatical parsing that is underway, and its understanding is pivotal to the successful achievement of the whole instruction.

The result of the coordination of the verbal products with their special prosodic features along with the bodily conduct yields not only an opening for what appears to be an emergent instructing project, but also to the recalibration of the mobilized semiotic resources into a particular configuration for a particular purpose ( $c f$. Goodwin, 2000: 1500). The composite of different modalities available to the interactants are part of the creation of a focal point building a mesh, or a 'semiotic node' (Radford et al., 2003). As such, it brings together the semiotic fields and centers on a grammatical word to be perceived/understood in a special way (see also Streeck, 1996: 366-7). Thus, a focal point for instruction is interactively accomplished.

So, based on the analysis so far, the instructing activity consists of singling out a word through both pointing and articulating it. The verbal production is with a coordinated prosody and marked intonation (here with a rising pitch, $c f$. Lerner, 1995). The action is also followed by a pause (line 2) as an interactional space where the recipient joins in, and completes the action of glossing it, thereby bringing it to a recognizable end. So, the learner confirms her understanding-so-far of the instructional focus (lines 3-7), i.e. making relevant a grammatical category at the moment which in this sequence is a 'plural noun'. This contextually shaped common understanding is reproducible and is repeated in the following sequence: 
Excerpt 1c. Learning Adverb: Tape Gn, D-level

Participants: Teacher (Tea) and Student (Stu)

08

09 Tea:

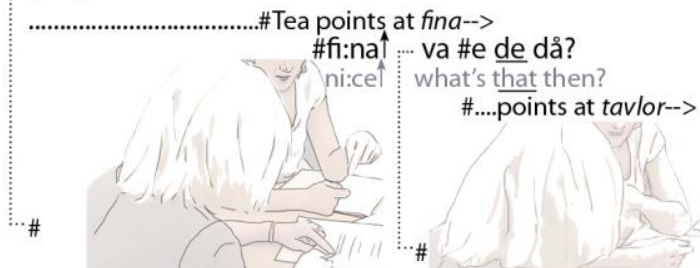

Fig. 5

10 Stu: aha: (.) fina, ja tror att de e tavlor aha: (.) nice, I believe that it's paintings

After establishing that the first component of the phrase is a plural noun, the teacher uses the understanding-so-far as a resource to move to the next sequence to deal with the next component of the noun phrase. She moves from 'tavlor' (paintings) to 'fina' (nice) and asks 'fi:na个 va e de då?' (ni:ce $\uparrow$ what is that then?) in which ' $d a ̊$ ' (then) marks the next step. This move is done through changing the focal point of the converging semiotic resources, i.e. the interactional focus made of verbal and nonverbal conduct, from 'tavlor' to 'fina' (line 8). During this transition, however, something goes wrong.

Despite the fact that the teacher acts almost exactly as she did in the first part, the student (line 10) does not provide a grammatical gloss for 'fina', as she did for 'tavlor'. The teacher points at 'fina', topicalizes it in her utterance, marks it with a rising pitch, and asks the question ' $v a$ e $\underline{d e}$ då?' (what is that then?) similar to what she did in foregrounding 'tavlor' through pointing and asking the question what the word is. Even though the student's response 'aha: (.) nice, I believe that it's paintings' (line 10) could have been relevant, it is incongruent with the previously established pattern of unpacking the noun phrase. 
A close observation of the teacher's turn through lines 8 and 9 would show how the change in the trajectory of pointing could be the reason for what went wrong in the first place:

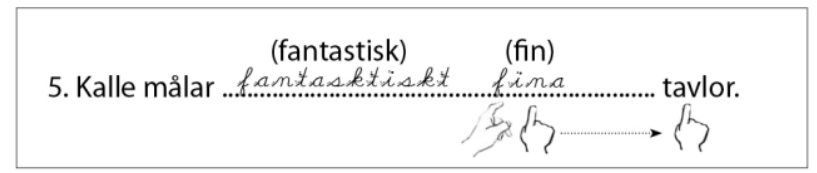

Fig. 7 The mobile pointing gesture changes the contextual configuration,
the loci of attention, and thus the trajectory of interaction.

The teacher's embodied practice in focusing on 'fina', which is visible through lines 8 and 9 , is observably different from her practice conducted on 'tavlor' in the previous sequence (line 1). The difference is related to the focal points in interaction. Unlike the first time, when she employed the available semiotic fields and convened them all accumulatively around one word, this time, she divides the focal points up between two words. At the end of the student's 'aha' (line 7), the teacher starts pointing at the word 'fina', with both hands (line 8). Her pointing gestures land and align just below the word 'fina' as she pronounces the word aloud (line 9, fig. 5). The teacher, then, moves her pen and points at the word 'tavlor' (fig. 6), and asks 'va e de da??' (what is that then?).

This partition of semiotic nodes (fig. 7), which is temporally timed with the production of the turn and spatially parse the visual field with a mobile pointing gesture, might have reflexively adjusted the student's action. This type of mobile pointing, which is drawn from one object to another may induce a link between the two. Such an understanding is evidenced by the student's response (line 10). She starts with a pre-initial 'aha' and at the same time, as she begins her turn, she points at the word 'fina' with her pen and moves it in a circle around the word. She does this until the moment in her utterance when she says 'fina, ja tror att de' (nice, I believe that it). She 
then beats on the word 'tavlor' and says 'e tavlor' (is paintings). The student practically proceeds along a possible instructed path which was instantiated in the teacher's pointing trajectory in the previous turn, and links two words 'fina' and 'tavlor' in response to the teacher's question (line 10, Stu: 'nice, I believe that it is paintings').

However, this is clearly not what the teacher asks for. In a corrective move which is initiated by the teacher in the following sequence, the student is invited to remedy her response and instead produce a grammatical gloss/category for the word 'fina'.

Excerpt 1d. Learning Adverb: Tape Gn, D-level

Participants: Teacher (Tea) and Student (Stu)

08

$(0.4)$

09 Tea:

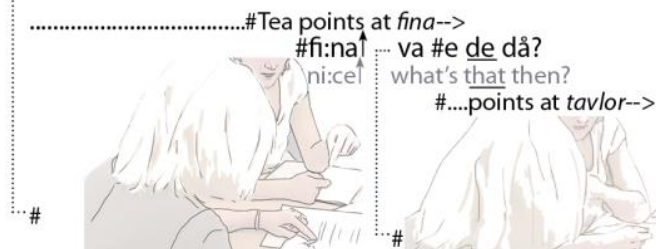

Fig. 5

10 Stu:

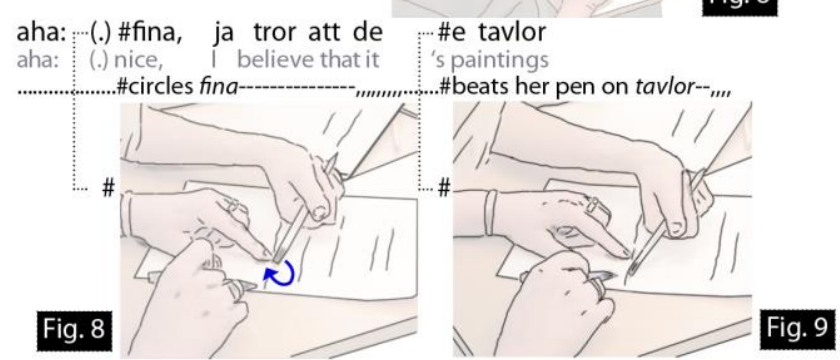

11 Tea:

A: allt så \#de e::, YEA:H s. that i::s,

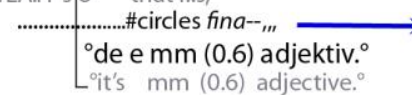

12 Stu:

13 Tea: adjekti:v, uhm

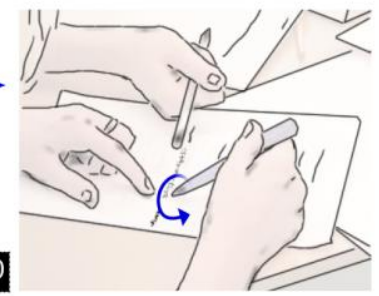


The student's hedging utterance (line 10) suggests that her response is just a candidate understanding (Schegloff, Jefferson \& Sacks, 1977), which is contingent on the confirmation or rejection by the teacher (see Schegloff, 2007: 31-34). The teacher, in return, makes some precision about where on the paper the student should look, and what the question is aimed at. She initiates a correction (Schegloff et al., 1977) to give another opportunity to the student to proactively resume the interactional line following the first sequence and treat ' $f$ ina' in a way that is relevant for the task at hand, i.e. to understand the phrase and its constituents ( $c f$. Linell, 2009: 380). The teacher produces an utterance consisting of both talk and gesture, in which the gesture pinpoints ' $f$ ina' as the locus of what is meant to be identified by the student. She moves her pen back to the word 'fina' where her left finger still is, and moves the pen a few times in a circle around 'fina'. In this way, she moves back the interactional focus to zero in on 'fina' as she says 'A: alltså de e::,' (YEA:H so it i::s, - fig 10).

The teacher mitigates the act of rejection by the initial acceptance of the student's response with a pro forma 'yes' (Schegloff, 2007: 70). She then initiates the remedy so that the student re-embraces the pre-established pattern (line 11). She gives the student a chance to correct her response by moving her pen a few times in a circle around the word 'fina'. She also elongates the pronunciation of the last word and marks it with a rising pitch which signals awaiting a response as a relevant next action ${ }^{1}$ ('i::s,' in line 11). Such a design of action, which is also constituted by a designedly incomplete turn constructional unit (TCU) is a pedagogical practice

\footnotetext{
${ }^{1}$ Furthermore, this seems to be generally preferred in the organization of interaction in similar settings where the student's noticing is preferred to the teacher's announcements (it could be compared to a similar general preference in everyday encounters, see Schegloff, 2007: 87-88 in the footnote).
} 
(Koshik, 2002), a 'recognizable, intonational, syntactical, and pragmatic' invitation to finish the rest of the turn ( $c f$. Lerner, 1995).

The student also reacts swiftly as 'an adequately informed recipient' at the moment (a display of being a good student perhaps) and corrects her response in the following turn (line 12). She now categorizes ' $f$ ina' as an 'adjective', which also gets aligned and agreed with by the teacher. This response is also used as a resource (a confirmed grammatical category) to warrant the next step in the progression of the instructional activity as a coherent whole.

In the third step of the instruction, before foregrounding the word 'fantastiskt' (wonderfully/fantastically) as the next item in the phrase, the teacher moves the interactional focus again to the words 'fina' and 'tavlor', pointing to them, and says 'då vet vi at fi:na tavlor e adjektiv.' (so we know that ni:ce paintings is adjective. - line 15). Pointing, once more, proves to be crucial in the assertion of what the teacher refers to as an adjective. When she claims that what might otherwise be seen as an adjective followed by a noun, 'fina tavlor', is an adjective, both her pointing gestures from below and above are at the word 'fina' on the worksheet (fig. 12). The pointing gestures are clearly an integral part of the reference to the categorized written object. Without them, the turn might have been unresolvably ambiguous.

Then, with the same technique of pointing steadily at the words, she holds her left index finger below and moves her pen in her right hand pointing from above at the word 'fantastiskt' (fig.13), and emphatically asks 'hu:r fina?' (ho:w nice?). This is shown in the multimodal transcription below. 
Excerpt 1e. Learning Adverb: Tape Gn, D-level

Participants: Teacher (Tea) and Student (Stu)

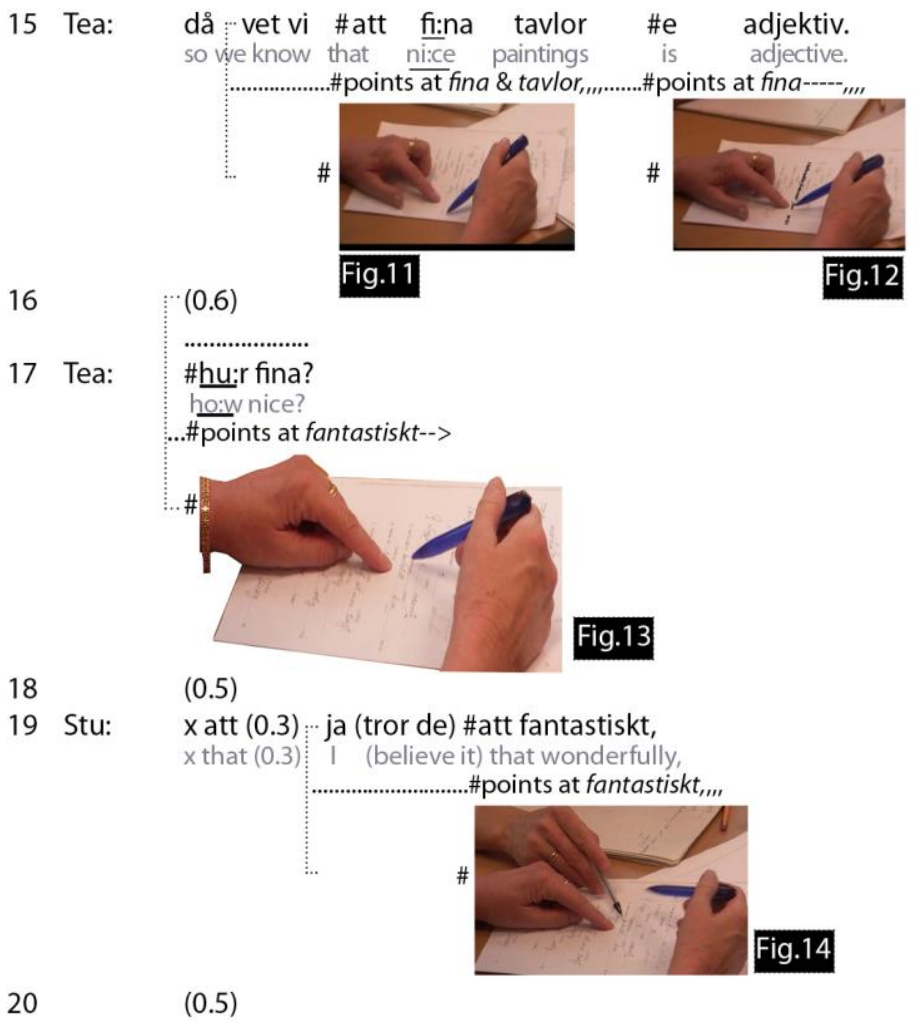




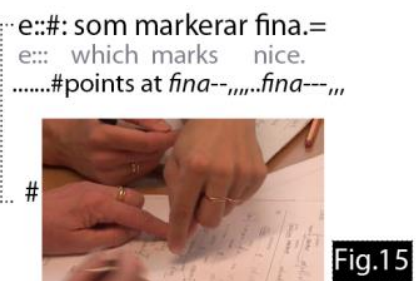

22 Tea: $\quad=\mathrm{j}$ a

23 Stu:

24 Tea:

$25 \quad(0.3)$

26 Tea: fantas tiskt fina tavlor

27 Stu:

28

e: e de e (till) $^{\circ}{ }^{\circ}$ ina $^{\circ}$ bestämmer fina $\mathrm{mm}$ (.) precis determines nice $\mathrm{mm}$ exactly

The previous sequences have paved the way for the design of the third one. Based on the design of the preceding actions, there seems to be 'bynow-familiar evidences' (Schegloff, 2007: 85) of an anticipatory initiation and response. However, the teacher's question is a bit different this time. She does not ask 'what is fantastiskt?', she rather instructs the student to hear that 'fantastiskt' is an adverb determining the howness of the rest of the noun phrase. She asks ' $\underline{h u: r}$ fina?' (how fine? - line 17) while pointing at 'fantastiskt' (wonderfully). The word 'hur' (how) formulates the adverbial character of the projected response, whereas the pointing gesture unequivocally specifies the lexical item that the student should use.

The question is responded to by the student in a multiunit turn (lines 19-23), accompanied by pointing and orienting to the rest of the noun phrase 'fina tavlor' (fig. 15) that, all in all, display an understanding of the detailed pattern of the sequence, the recognition of the learnable, and the accomplishment of the whole instructing activity. The student's proactive orientation to the learnable is manifest when she answers that she believes that 'fantastiskt' modifies 'fina' (lines 19-21). This gets immediately 
confirmed by the teacher (line 22), while she repeats the rationale and specifies that the adverb determines the adjective (line 24$)^{2}$.

A local achievement of the understanding of the grammatical glosses and relations, one can see in the presented data, is only made possible through the embodied and endogenous practices as well as active participation for actualizing the instructed actions in and through those practices. Such an understanding is accessible only through the procedural progression of the instructed actions and the order of the organization of the activity. The accomplishment of a learnable as the achievement of the whole activity is not only made of what the teacher instructs but of what the student, too, competently follows, co-builds and achieves. The clarity of the outcome of the instruction, therefore, lies in the granularity of the sequences and actions, which the student and the teacher together, cogently and conjointly, have gone through.

The sequential format of this data could be described as follows: a lexical item on a piece of paper is pointed at/foregrounded by the teacher. In response, it gets recognized/announced/formulated by the student invoking its grammatical gloss. This may be confirmed or rejected, and/or negotiated further until the relevant response gets validated ( $c f$. Majlesi \& Broth, 2012). This sequence could proceed with some incremented turns as a sequence-closing action which, in the presented data, is the display of an epistemic-receipt-signal (but not necessarily a change of the state of knowledge $c f$. Heritage, 1984) that treats the sequence as complete (for instance, line 7 ' $a h a$ ' for the first sequence, line 13 ' $u h m$ ' for the second sequence and line 27 ' $a$ :' for the third sequence).

\footnotetext{
${ }^{2}$ The teacher's confirmation is followed by another pedagogical lesson for the student. The teacher's response confirming the student's understanding (line 24) contains an embedded correction (Jefferson, 1987). She corrects the student's formulation and replaces the verb in the student's utterance, 'marks' (markerar line 21), with another verb ,'determines' (bestämmer - line 24).
} 
So the pattern of the analyzed sequences could be described as follows:

- A: bringing attention to a written lexical item (invoking a grammatical gloss)

- B: exhibiting a candidate understanding

- A: confirming/validating

- B: displaying/(re-)affirming the understanding

Or

- A: bringing attention to a written lexical item (invoking a grammatical gloss)

- B: exhibiting a candidate understanding

- A: rejecting/(initiating) repair

- B: exhibiting a new candidate understanding

- A: confirming/validating

- B: displaying/(re-)affirming the understanding

\subsection{Embodied practices in producing a correct grammatical agreement}

The next example is a correction sequence (Macbeth, 2004; Kurhila, 2006; cf. also Keevallik, 2010; Lindwall \& Ekström, 2012) where the teacher brings the student's attention to the mistake he has made in his written sentence. The sentence is part of a short passage in Swedish that the student has written as a task. The transcript starts at a point in the conversation when they have already solved a spelling problem in the same sentence.

The focus here is on the sentence 'han slutade hans doktorand' (he ceased/finished his doctoral candidate). The sentence has a few obvious 
discussable issues including word choice and meaning, but what gives rise to the following conversation is the problem of agreement between the subject pronoun 'han' and the possessive pronoun 'hans', which is used along with a noun shaping the object of the sentence. In Swedish, the option between two types of third person possessive pronouns (for instance hans or sin in the presented case) is reflexively tied to the subject of the same sentence/utterance. If the subject and; if not, 'hans' is in order. This was a grammatical point that the students were taught previously. The teacher now initiates talk to draw the student's attention to notice a problem in his sentence that is related to this distinction. As it is shown in excerpt $2 \mathrm{a}$, this is done through embodied actions:

Excerpt 2a. Possessive Pronoun: Tape En, D-level

Participants: Teacher (Tea) and Student (Stu)

01 Tea: just de:-va våar de \#här då? right what's it written here then?

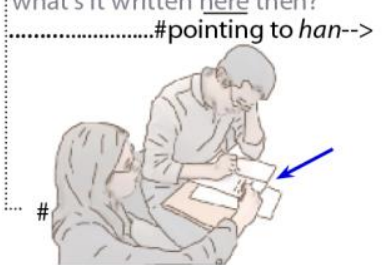

02

Fig.16

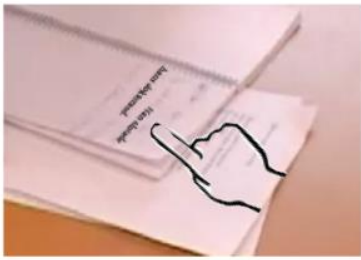

Fig.17

03 Tea:

04 Stu:

05

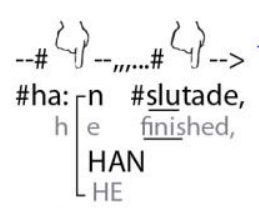

(0.4)
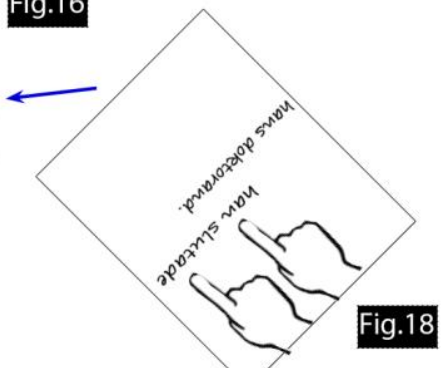

Fig.18

This sequence is nested within a longer stretch of interaction between the teacher and the student centering on the student's written text. This particular sequence starts with a $0.5 \mathrm{~s}$ pause after the completion of the previous sequence/action (the teacher and the student talked about a 
misspelling problem which was solved and the sequence was manifestly closed). The teacher opens this sequence with 'just de' (right) as a 'turnentry device' (Sacks et al., 1974), which is also a multifunctional particle in Swedish, displaying connectivity with the previous turn, and showing agreement or alignment, and signaling a preface to upcoming talk, among other things. Here, it could also be construed as an indicator of a news- or noteworthy event or problem, comparable to the epistemic token of 'oh' (Heritage, 1984: 324). In the context of this data, 'just de' seems to be responsive to the situational relevancy of something which was found remarkable in the text.

Immediately after saying ' just de', the teacher begins to point at ' $h a n$ ' (he) in the text, and asks 'va står de här då?' (what is it written here then?). The pointing finger which starts with the production of ' $v a$ ' (line 1, fig. 16) lands on the written word 'han' (he) in the middle of the articulation of the word 'står', that is followed by the stressed deictic ' $h \ddot{a} r$ ' (here). This is a conspicuous performance not only singling something out of the text, and not only 'physically connecting' the stream of speech to that object as visible, locatable, describable, or 'computable' (H. Clark, 1996: 165), but also grounding a basis for a prospective learnable. The learnable, however, is not yet realized but its account is forthcoming in the next actions. The teacher's pointing could not be understood without paying attention to all contextual features making up the relevant semiotic node which includes not only the bodily conduct and the verbal resource ('va står de här då?') but also the object of inquiry itself on the worksheet ( $c f$. Streeck, 1996; Goodwin, 2007: 196).

Similar to the 'learning adverb' data, the question that the teacher asks is contexted in the activity of instruction with reference to the structure of the grammatical construct written on the paper. The question, too, in a similar fashion, interactionally invites the student to have an opportunity to 
realize 'what is there on the worksheet to notice', even though it is ambiguous whether the teacher asks the student to read the word that she is referring to, or whether there is something more to it.

However, unlike the 'learning adverb data', where the teacher's pointing and the question gave the straight cues about the source of inquiry, here the teacher's question and the gesture do not directly indicate what the teacher 'actually' points out. Even though the activity type may help inferring that the teacher refers to a 'potential problem' in the text, the lack of specificity may account for the delay in the response (line 2) or the production of an incomplete or undesirable response (line 4). This, in turn, requires further interactional effort such as the expansion or revision of the action by the teacher.

At this moment, perhaps in order to offer an interactional space to the student to recognize the object of inquiry, the teacher keeps her finger on the surface of the paper pointing at the word 'han'. A missing response after $0.5 \mathrm{~s}$ probably prompts the teacher to show the target of her pointing more vividly. The teacher starts reading the written sentence, word by word, pointing at each word while reading it (line 3): she reads and points at ' $h a n$ ', then moves her finger to point at 'slutade' and reads it, then she stops and leaves the floor to the student again. The teacher's stopping after 'slutade' while still pointing steadily at 'hans' is a clear cue to show what comes next should reveal the problem.

Just as in the 'learning adverb data', here, the invitation for the recipient to join in the conversation ( $c f$. Lerner, 1995) is also manifest in the emphatic stress on the first syllable and the rising pitch on the last syllable of the word 'slutade,' which is followed by a pause (line 5). Pointing at the written sentence and simultaneously reading it word by word solicits, directs and secures the gaze of the recipient in the pursuit of the teacher's finger which trails on the paper from one word to another. In 
this way, the focal point of interaction moves on the worksheet to where the pointing is directed.

This reading procedure, first with pointing to the word and then with articulating it out loud, has kept the gaze of the student on the worksheet. In fact, the state of mutual gaze is appropriated after the type of the activity (Goodwin, 1981; cf. Mondada, 2007), and gazes are directed merely toward the words that are pointed at.

When the student starts to follow the teacher's action by pointing to and reading the rest of the sentence 'hans doktorand' (his doctoral candidate line 6), the incongruence between 'han' (the subject of the phrase) and 'hans' (the badly fitted possessive pronoun), based on previously taught lessons, should probably - and hopefully - appear as problematic to him. However, the student gets past the problem without showing any recognition of it. The teacher, then, steps in once more:

Excerpt 2b. Possessive Pronoun: Tape En, D-level

Participants: Teacher (Tea) and Student (Stu)

06

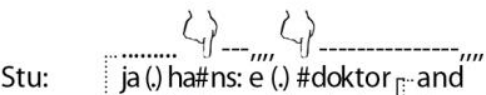

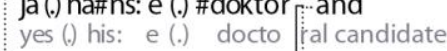

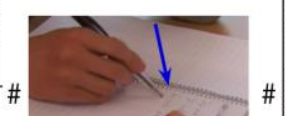

Fig.19

\#

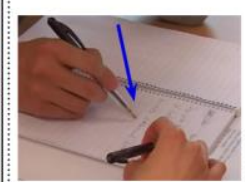

Fig.20

07 Tea:

hh JA\#

hh YES

..\#points to hans $-\rightarrow$

08 Stu: $\quad{ }^{\circ} \mathrm{ja}^{\circ}=$ 


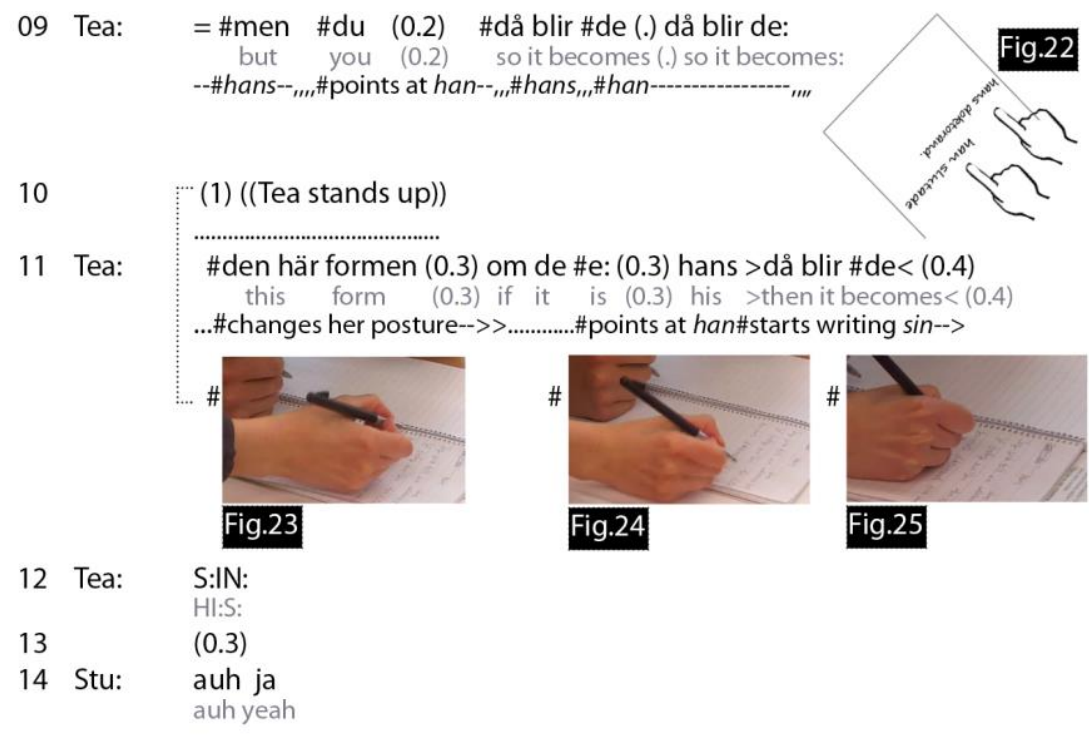

As shown in the multimodal transcription (lines 7 and 9), to foreground the relevant grammatical relation, i.e. the learnable, the teacher moves her pointing finger back and forth (figs. 21 and 22), between 'han' (he) and 'hans' (his). This mobile linker pointing provides a new constellation of the semiotic resources, configuring the focus of instruction in a certain way. In fact, the pointing gesture, as it was also shown in the previous example, foregrounds not only two visible written objects (han and hans), but also their particular grammatical relationship. Pointing in this sense not only indexes something concrete on the surface of the worksheet but also reflexively foregrounds certain metalinguistic categories, rules and relationships, and creates some abstract target.

This linker pointing has also a reflexive effect on the details of how the teacher embodies her action ( $c f$. Mondada, 2007: 212). First, in the teacher's turn construction, the pointing allows a turn-entry before the talk begins (line 7). The teacher's entering hand and moving on the visual field permits or facilitates her seizing the floor (it accountably projects a turn). Second, the continuous move of the pointing fingers linking the two words 
in the syntactic structure of the sentence signals a signification that lies in the visibly highlighted ties between these two words. Third, the linker pointing gesture also projects that the next turn(s) will be dealing with the underlying relations of the two. This is the act of foregrounding a prospective learnable at the moment.

The account for what should be noticed, recognized, corrected and learned comes in the subsequent turn where the teacher takes over the whole worksheet, changes her posture (i.e. she stands up, line 10), and assumes a position to write down something on the worksheet (at the beginning of line 11), and at the same time she begins to invoke the grammatical rule relevant to such a relationship between the subject pronoun and its direct object with a third person possessive pronoun. She says (line 11) 'if it is hans (his) then it becomes SI:N:', which implies that if the object belongs to the same subject, then 'sin' should be used ${ }^{3}$, and at the same time writes it down on the worksheet (lines 11 and 12). This sequence gets completed and closed by the epistemic token of 'auh yeah' that the student produces (line 14), which has a flavor of a sign of remembering already-known information ( $c f$. Heritage, 1984).

\section{Summary: Instructing grammar on a worksheet}

The grammatical learnables' existence and emergence are a step-by-step procedural accomplishment in the granularity of instructed actions. The analysis has shown how learnables, as positioned in the initial turn of a sequence/action, may be indexically prospective when they are not yet realized and accounted for but referred to and pointed at on the paper. Their

\footnotetext{
${ }^{3}$ The account that the teacher provides to explain why the student needs to write 'sin' in instead of 'hans' in the sentence is by presenting the rationale that if it (the object) belongs to him (the subject) then the possessive pronoun should be 'sin'. She says (line 11): 'om de e hans då blir de SIN' (if it is his, then it becomes sin).
} 
accounts in the upcoming turns or sequences may not be merely done through talk, but also in an embodied way. They are anchored in the instructed actions, in what comes next. Thus, under the auspices of the unfolding sequence, learnables are understood and exhibited not just as something seen or heard, but something just seen or heard as special categories, glosses, concepts, etc.

In cases where learnables are not announced aloud or proactively recognized by the learner (Majlesi \& Broth, 2012), embodied conduct, especially pointing gestures, prove to be pivotal to foregrounding and recognizing them. They may also change the trajectory of actions, the course of instruction and the understanding of the rationale behind the action.

Pointing gestures (stable and mobile) are employed through different practices (localizing, place-holding or linking) with different temporal and spatial trajectories, for different actions (drawing attention, parsing, foregrounding a grammatical structure/concept/relation, aligning, showing understanding, instructing, following the instruction, etc.) through accountable motions. Not only do they refer to the visible grammatical constructs on the worksheets, they also indexically project the upcoming operations on the linguistic items, help symbolically transform them ( $c f$. Streeck, 1996), and reflexively change the contextual specificity of them by foregrounding their abstract grammatical glosses, categories or relations.

The instructing activity on the whole consists of the progressive accomplishment of learnables through embodied and endogenous actions. Such an accomplishment may be exhibited through a display of understanding the rationale behind the instruction with a verbal and/or written resolution/formulation of the co-achieved learnables. 


\section{Conclusion: seeing grammatically}

This study has provided a descriptive analysis of a progressive implementation of a social praxis which paves the way for the instruction of grammar and following it in co-present face-to-face interaction. In instructing grammar on a worksheet, it is shown that to reach a linguistic 'awareness' about grammatical learnables, the student is required to see and understand the grammatical features of the words on the paper. This is achieved through an interactive instruction, i.e. the constant engagement in instructed actions as emergent embodied accomplishments.

What-there-is-on-the-paper-to-learn is, therefore, accomplished through co-operated actions. That is, the abstract grammatical relations and categories are made concrete and tangible for the students of a second language through the use of temporally organized and recognizably observable material actions. The actions and co-actions, which are complex and multi-modal, publicly make visible the 'inclusion of, awareness of, use of, things' (Sacks, 1992a: 740) that are exhibited as orientable, explainable, generalizable (for future use), and also as learnable for all practical purposes.

This interactionally accomplished and displayed awareness is a property central to the understanding of each action and, thus, to the progression of the sequences in the whole instructing project. It underscores that awareness is not simply a mental process (e.g. Grass \& Selinker, 1994/2008; Krashen, 1981) but also 'a public, visible component of the ongoing practices' (Goodwin, 2000: 1503-4) which are used to build entire courses of action. Thus, the completion of the whole instruction, and probably its success, lies in the provision of an interactional space for the display of such an awareness. 
Therefore, instructing grammar on a worksheet is more than passing on the system-internal rules of a language to the language learners as input (Krashen, 1981; Gass \& Selinker, 1994/2008). It is also beyond a simple exchange of asking, answering and providing feedback in an extendable question-answer sequence (see also Mehan, 1979 on IRE). The analysis clearly shows that other communicative resources should be taken into account to begin to understand the lived reality of situated grammar teaching. Here, the instruction is 'a wittnessably achievable proposal' (Garfinkel, 2002: 204), which is only actualized through systematic coordinated actions. These actions are progressively organized from moment to moment, from one action to the subsequent one until the entirety of the instruction is conjointly shaped.

Semiotic resources employed in doing grammar instruction may include worksheets, gestures and accompanying talk. Instead of considering the role of some of these resources as peripheral or ancillary to the main courses of action, the analysis shows the integrated nature of multi-modal instructed actions and their crucial roles in the accomplishment of the whole instruction. Without the intertwinement of those resources, the transposition of the abstracted grammatical relations onto tangible and visible objects on the paper would not be achieved.

Furthermore, the analysis shows that the method of providing an interactional space for the student to learn a grammatical point (see scaffolding in Bruner, 1975; see also the Zone of Proximal Development in Vygotsky, 1978; $c f$, Donato, 2000: 46) involves mutually achieved actions which may not be fully described generally as an assistance supplied to learners to facilitate their performance ( $c f$. Ohta, 2000: 52). It is rather a meticulous interactional coordination, a hands-on practice, and an embodied collaboration to build, step by step, grammatical understanding. 
Instructing grammar, therefore, emerges as a procedural activity in and through its order of organization. That is, how a word is linguistically

glossed, what a linguistic form should be seen-as, and how the relations of the components of that grammatical structure are understood are all progressively achieved instructionally and interactively. Such a 'gestalt' shapes a distinctive way of seeing, knowing and understanding which may be seen as an instructed vision heuristically elicited from actions, and methodically brought into being by an achieved coherence of acts upon the linguistic objects.

\section{Acknowledgments}

I am very thankful to the SFI students, as well as the teachers who helped me with, and participated in, the video recordings that shaped the data used for this study.

In the process of writing this paper, I benefited from the scholarly ideas that I received from Mathias Broth, Per Linell, and Charlotta Plejert. I am indebted to their comments, and observations that helped me develop this article. I express my gratitude to Asta Cekaite for her helpful comments on an earlier version of this article. I extend my sincere thanks to Charles Goodwin, and Lorenza Mondada for sharing with me their most useful ideas regarding the presented data in this research.

I am also very appreciative to the two anonymous reviewers for their comments and critiques which helped me to improve on the previous version of the paper. 


\section{References}

Alibali, Marta W., Kita, Sotaro, Young, Amanda J., 2000. Gesture and the process of speech production: We think, therefore we gesture. Language and Cognitive Processes, 15, 593-613.

Broth, Mathias, Mondada, Lorenza, 2013. Walking away: The embodied achievement of activity closings in mobile interaction. Journal of Pragmatics, 47, 41-58.

Bruner, Jerome S., 1975. The ontogenesis of speech act. Journal of Child Language, 2, 1-19.

Churchill, Eton, Okada, Hanako, Nishino, Takako, Atkinson, Dwight, 2010. Symbiotic gesture and sociocognitive visibility of grammar in second language acquisition. The Modern Language Journal, 94, 234253.

Clark, Andy, 2001. Mindware. An introduction to the philosophy of cognitive science. Oxford: Oxford University Press.

Clark, Herbert H., 1996. Using language. Cambridge: Cambridge University Press.

Donato, Richard, 2000. Sociocultural contributions to understanding the foreign and second language classroom. In James P. Lantolf (Ed.), Sociocultural theory and second language learning, (pp. 27-50). Oxford: Oxford University Press.

Efron, David, 1941/1972. Gesture, Race and Culture. The Hague: Mouton. Firth, Alan, Wagner, Johannes, 1997. On discourse, communication and (some) fundamental concepts in second language acquisition research, The Modern Language Journal, 81 (3), 285-300. 
Gagné, Nathalie, Parks, Susan, 2013. Cooperative learning tasks in a grade 6 intensive ESL class: Role of scaffolding. Language Teaching Research, 17(2), 188-209.

Garfinkel, Harold, 1967. Studies in Ethnomethodology. New Jersey: Prentice Hall Inc.

Garfinkel, Harold, 2002. Ethnomethodology's Program. Working out Durkheim's Aphorism. New York: Rowman and Littlefield.

Garfinkel, Harold, Bitnner, Egon, 1967. "Good" organizational reasons for "bad" clinic records. In Harold Garfinkel (Ed.), Studies in Ethnomethodology. New Jersey: Prentice Hall Inc.

Gass, Susan, M., Selinker, Larry, 1994/2008. Second language acquisition - an introductory course. New York: Routledge.

Gass, Susan M., Svetics, Ildiko, Lemelin, Sarah, 2003. Differential effects of attention. Language Learning, 53, 497-545.

Goodwin, Charles, 1981. Conversational organization. Interaction between speakers and hearers. New York: Academic Press.

Goodwin, Charles, 1994. Professional vision. American Anthropologist, 96(3), 606-633.

Goodwin, Charles, 1996. Transparent vision. In Elinor Ochs, Emanuel A. Schegloff, \& Sandra Thompson (Eds.), Interaction and Grammar, (pp. 370-404). Cambridge: Cambridge University Press.

Goodwin, Charles, 2000. Action and embodiment within situated human interaction. Journal of Pragmatics, 32, 1489-522.

Goodwin, Charles, 2007. Environmentally coupled gesture. In. Susan D. Duncan, Justine Cassell, \& Elena T. Levy (Eds.), Gesture and the dynamic dimension of language, (pp. 195-212). Amsterdam: John Benjamins.

Goodwin, Charles, 2013. The co-operative, transformative organization of human action and knowledge. Journal of Pragmatics, 46, 8-23. 
Gullbeg, Marianne, 2008. Gestures and second language acquisition. In. Peter Robinson \& Nick C. Ellis (Eds.), Handbook of cognitive linguistics and second language acquisition, (pp. 276-305). New York: Routledge.

Gullberg, Marianne, McCafferty, Steven G., 2008. Introduction to gestures and SLA: toward an integrated approach. Studies in Second Language Acquisition. 30, 133-146.

Hall, Joan, K., Hellermann, John, Pekarek Doehler, Simona, 2011. L2 interactional competence and development. Kindle Edition. Bristol: Multilingual Matters.

Heritage, John, 1984. A change of state token and aspects of its sequential placement. In J. Maxwell Atkinson \& John Heritage (Eds.), Structure in social action - Studies in conversation analysis, (pp. 299-345). Cambridge: Cambridge University Press.

Heritage, John, Sorjonen, Maira-Leena, 1994. Constituting and maintaining activities across sequences: and-prefacing as a feature of question design. Language in Society, 23, 1-29.

Jefferson, Gail, 1987. On exposed and embedded correction in conversation. In Graham Button \& John R. E. Lee (Eds.), Talk and social organization, (pp. 86-100).Clevedon, England: Multilingual Matters.

Keevallik, Leelo, 2010. Bodily quoting in dance correction. Research on Language and Social Interaction, 43, 4, 401-426.

Kendon, Adam, 1990. Conducting interaction - Patterns of behavior in focused encounters. Cambridge: Cambridge University Press.

Koschmann, Timothy, D., 2011. Theories of learning and studies of instructional practices. New York, NY: Springer. 
Koshik, Irene, 2002. Designedly incomplete utterances: a pedagogical practice for eliciting knowledge displays in error correction sequences. Research on Language and Social Interaction, 35(3), 277-309.

Krashen, Stephen, D., 1981. Second language acquisition and second language learning. Oxford: Pergamon Press.

Kurhila, Salla, 2006. Second language interaction. Amsterdam: John Benjamins.

Latour, Bruno, Woolgar, Steve, 1979. Laboratory life. The construction of scientific facts. Princeton: Princeton University Press.

Lazaraton, A. (2004). Gesture and speech in the vocabulary explanations of one ESL teacher: A microanalytic inquiry. Language Learning, 54(1), 79-117.

Lerner, Gene H., 1995. Turn design and the organization of participation in instructional activities. Discourse Processes, 19, 111-131.

Lindwall, Oskar, Ekström, Anna, 2012. Instruction-in-interaction: The teaching and learning of a manual skill. Human Studies, 35, 27-49.

Linell, Per, 2009. Rethinking language, mind and world dialogically interactional and contextual theories of human sense-making. Charlotte, NC: Information Age Publishing Inc.

Macbeth, Douglas, 2004. The relevance of repair for classroom correction. Language in Society, 33, 703-736.

Majlesi, Ali Reza, Broth, Mathias, 2012. Emergent learnables in second language classroom interaction. Learning, Culture and Social Interaction, 1, 193-207.

Markee, Numa, 2000. Conversation analysis. Mahwah, NJ: Erlbaum.

McNeill, David, 1992. Hand and Mind: what Gestures Reveal about Thought. Chicago: University of Chicago Press.

Mehan, Hugh, 1979. Learning lessons: social organization in the classroom. Cambridge, MA: Harvard University Press. 
Melander, Helen, 2012. Transformation of knowledge within a peer group. Knowing and learning in interaction. Learning, Culture and Social Interaction, 1, 232-248.

Mondada, Lorenza, 2007. Multimodal resources for turn-taking: pointing and emergence of possible next speakers. Discourse Studies, 9(2),194225.

Mondada, Lorenza, 2010. Understanding as an embodied, situated and sequential achievement in interaction. Journal of Pragmatics, 43, 542552.

Mondada, Lorenza, 2012. Video analysis and the temporality of inscriptions within social interaction: the case of architects at work. Qualitative Research, 12(3), 304-333.

Mondada, Lorenza, Pekarek Doehler, Simona, 2004. Second language acquisition as situated practice: task accomplishment in the French second language classroom. The Modern Language Journal, 88(4), $501-18$.

Mori, Junko, Hayashi, Makoto, 2006. The achievement of intersubjectivity through embodied completions: a study of interaction between first and second language speakers. Applied Linguistics, 27(2), 195-219.

Ohta, Amy Snyder, 2000. Rethinking interaction in SLA: developmentally appropriate assistance in the zone of proximal development and the acquisition of L2 grammar. In James, P. Lantolf (Ed.), Sociocultural theory and second language learning, (pp. 51-78). Oxford: Oxford University Press.

Radford Luis, Demers, Serge, Guzmán, José, Cerulli, Michele, 2003. Calculators, graphs, gestures and the production of meaning. In Neil A. Pateman, Barbara, J. Dougherty, \& Joseph T. Zilliox (Eds.), Proceedings of the 27 conference of the international group for the 

$55-62$.

Sacks, Harvey, 1992a \& b. Lectures on conversation, vols. 1 and 2. Oxford: Blackwell.

Sacks, Harvey, Schegloff, Emanuel. A., Jefferson, Gail, 1974. A simplestsystematics for the organization of turn taking for conversation, Language, 50, 696-735.

Sahlström, Fritjof, 2011. Learning as social action. In. Joan K. Hall, John Hellermann, \& Simona Pekarek Doehler (Eds.), L2 interactional competence and development, (pp. 43-63). Kindle Edition. Bristol: Multilingual Matters.

Schegloff, Emanuel A., 2007. Sequence organization in interaction. A primer in conversation analysis. Vol. 1. Cambridge: Cambridge University Press.

Schegloff, Emanuel A., Jefferson, Gail \& Sacks, Harvey 1977. The preference for self-correction in the organization of repair in conversation, Language, 53, 361-82.

Schmidt, Richard, 2001. Attention. In Peter Robinson (Ed.), Cognition and Second Language Instruction. Cambridge: Cambridge University Press.

Seo, Mi-Suk, 2011. Talk, body, and material objects as coordinated interactional resources in repair activities in one-on-one ESL tutoring. In Gabriele Pallotti \& Johannes Wagner (Eds.), L2 learning as social practice - conversation-analytic perspective, (pp. 107-134). Honolulu, Hawaii: National Foreign Language Resource Centre, University of Hawaii at Mānoa.

Seedhouse, Paul, 2004. The interactional architecture of the language classroom. Malden, MA: Blackwell. 
Singer, Melissa A., Goldin-Meadow, Susan, 2005. Children learn when their teacher's gestures and speech differ. Psychological Science, 16, 85-89.

Streeck, Jürgen, 1996. How to do things with things. Human Studies, 19(4), 365-384.

Svinhufvud, Kimmo, Vehviläinen, Sanna, 2013. Papers, documents, and the opening of an academic supervision encounter. Text and Talk, 33(1), 139-166.

Szczepek, Reed, Beatrice, Reed, Darren, Haddon, Elizabeth, 2013. NOW or NOT NOW: Coordinating restarts in the pursuit of learnables in vocal master classes. ROLSI, 46(1), 22-46.

Swain, Merrill, 1985. Communicative competence: some roles of comprehensible input and comprehensible output in its development. In Susan Gass \& Carolyn G. Madden (Eds.), Input in second language acquisition, (pp. 235-253). Rowley, MA: Newbury House.

Swedish Research Council, 2011. Good Research Practice. Stockholm: Vetenskapsrådet (Swedish Research Council).

Vygotsky, Lev Semenovich, 1978. Mind in society. The development of higher psychological processes. Cambridge, MA: Harvard University Press.

Weber, Max, 1968/1978. Economy and society: an outline of interpretive sociology. Berkeley: University of California.

White, Lydia, 2003. Second language acquisition and universal grammar. Cambridge: Cambridge University Press.

Wittgenstein, Ludwig, 1953/2009. Philosophical investigation, Gertrude Elizabeth Margaret Anscombe, Peter Michael Stephen Hacker \& Joachim Schulte (Trans.). Malden, MA: Wiley-Blackwell.

Zemel, Alan, Koschmann, Timothy, 2014. Put your fingers in there: Learnability and instructed experience. To appear in Discourse Studies. 


\section{Appendix: Transcription Conventions}

\begin{tabular}{|c|c|}
\hline[ & left square bracket: a point of overlap onset \\
\hline$=$ & $\begin{array}{l}\text { equal signs: } 1 \text { two lines are connected } 2 \text {. one turn is } \\
\text { latched by another }\end{array}$ \\
\hline$(0.5)$ & $\begin{array}{l}\text { numbers in parentheses: silence, represented in tenths of a } \\
\text { second }\end{array}$ \\
\hline (.) & $\begin{array}{l}\text { a dot in parentheses: a micro-pause (usually less than } 0.2 \\
\text { seconds) }\end{array}$ \\
\hline . & period: falling intonation \\
\hline ? & question mark: rising intonation \\
\hline , & comma: continuing intonation \\
\hline$i$ & $\begin{array}{l}\text { inverted question mark: a rise stronger than a comma but } \\
\text { weaker than question }\end{array}$ \\
\hline$:::$ & colons: prolongation or stretching of the sound \\
\hline- & $\begin{array}{l}\text { hyphen: after a word or part of a word indicates a cut-off } \\
\text { or self-interruption }\end{array}$ \\
\hline$\underline{\text { Word }}$ & $\begin{array}{l}\text { underlining: stress or emphasis by increased loudness or } \\
\text { higher pitch }\end{array}$ \\
\hline $\begin{array}{l}\text { WOR } \\
\text { D }\end{array}$ & all capital letters: much louder than the surrounding words \\
\hline$\circ \circ$ & degree signs: the word is markedly quiet or soft \\
\hline$\uparrow \downarrow$ & up and down arrows: sharper rise or fall in pitch \\
\hline
\end{tabular}




\begin{tabular}{|c|c|}
\hline$><$ & more than, less than: with a jump-start, said in rush quickly \\
\hline$<>$ & less than, more than: is markedly slowed or drawn out \\
\hline Hhh & out-breath: laughter in voice \\
\hline .hhh & in-breath \\
\hline$(())$ & double parentheses: transcriber's comments \\
\hline (word & utterance in parentheses: transcription is not certain \\
\hline$($ ) & $\begin{array}{l}\text { empty parenthesis: something is being said, but no hearing } \\
\text { can be achieved } \\
\text { On occasion I also use the following multimodal } \\
\text { transcription symbols: }\end{array}$ \\
\hline ..... & described gesture's preparation \\
\hline----- & gesture's preparation apex is reached and maintained \\
\hline,, & gesture's retraction \\
\hline$--->$ & $\begin{array}{l}\text { gesture or action described continues across subsequent } \\
\text { lines }\end{array}$ \\
\hline$---->>$ & $\begin{array}{l}\text { gesture or action described continues until and after } \\
\text { excerpt's end }\end{array}$ \\
\hline \# & $\begin{array}{l}\text { with a specific sign showing its position within a turn at } \\
\text { talk }\end{array}$ \\
\hline
\end{tabular}

